\title{
Are we meeting the HIV service needs of people living in informal settlements in Kwazulu-Natal, South Africa?
}

Project SOAR

Follow this and additional works at: https://knowledgecommons.popcouncil.org/departments_sbsr-hiv

Part of the Demography, Population, and Ecology Commons, Family, Life Course, and Society Commons, International Public Health Commons, and the Medicine and Health Commons How does access to this work benefit you? Let us know!

\section{Recommended Citation}

Project SOAR. 2017. "Are we meeting the HIV service needs of people living in informal settlements in Kwazulu-Natal, South Africa?" Results brief. Washington, DC: Population Council. 


\section{Are We Meeting the HIV Service Needs of People Living in Informal Settlements in Kwazulu-Natal, South Africa?}

Communities in South Africa's informal settlements consist of ad-hoc and improvised housing whose residents seek opportunities for employment in the surrounding area. While many are recent migrants with a high degree of mobility, some residents live their entire lives in these communities. It is estimated that nearly 400,000 people live in informal settlements in KwaZuluNatal province alone (Housing Development Agency 2013). Since the settlements are unplanned, they are often underserved by municipal services, are under-represented politically, and lack accessible healthcare and economic opportunities. This can create an environment that increases residents' risks for HIV and sexual and gender-based violence.

This brief summarizes the characteristics and circumstances of approximately 1,500 men and women living in 18 informal settlements in KwaZulu-Natal. The data come from a baseline survey conducted in mid-2017 as part of an evaluation of the PEPFAR/USAID-funded Asibonisane Community Responses program. ${ }^{1}$ Project SOAR/Population Council is conducting the evaluation in partnership with MatCH Research Unit at the University of Witwatersrand. Final results from the evaluation will be available in 2019.

${ }^{1}$ Additional findings from the baseline survey can be found in the companion brief, "Gender norms and power dynamics: Potential barriers to HIV treatment uptake in informal settlements in South Africa."

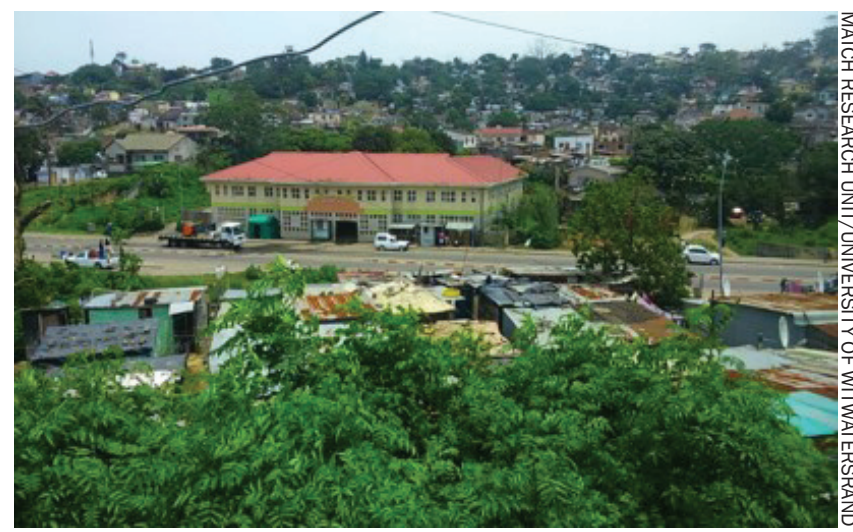

Informal settlement in KwaZulu Natal

\section{ASIBONISANE COMMUNITY RESPONSES PROGRAM}

The Asibonisane Community Responses program, implemented by the Centre for Communications Impact, and partners DramAide and The Valley Trust (in KZN), is a multifaceted behavior change intervention focused on young adult men and women living in informal settlements in South Africa. The program aims to promote the adoption of safe sexual behaviors, and uptake of HIV prevention, testing, and treatment services. The program also seeks to promote equitable gender norms and a positive enabling environment to reduce sexual and genderbased violence. More information about the Community Responses program is available at: ccisa.org.za/current-projects.html. 


\section{WHO ARE THE STUDY PARTICIPANTS?}

768 females ages 18-24 (mean age 21)

758 males ages 18-35 (mean age 25)

90\% attended secondary school; very few completed a university degree

\section{ECONOMIC INSECURITY AND MOBILITY}

- Earnings: More than half of men (57 percent) and women (53 percent) reported earning no income in the last 30 days. Among women reporting an income, two-thirds said the primary source was a social grant to children. Men are higher earners than women: 74 percent of men compared to 14 percent of women reported a monthly income greater than ZAR 1,500 (about USD 112).

- Borrowing: Between 42 and 47 percent of residents would have difficulty borrowing ZAR 200 (about USD 15) in an emergency.

- Food insecurity: About 20 percent women and 33 percent of men said they or a member of their household didn't eat for at least one day in the past four weeks.

- Mobility: 40 percent of women and 27 percent of men have been residents for less than 2 years; 17 percent of men, compared to 12 percent of women, had slept away from the community for more than 30 days during the last 6 months.

\section{TYPES OF PARTNERSHIPS AND CONDOM USE}

- Primary partnerships: The majority of respondents currently have a primary sexual partner, with more woman reporting this type of partnership than men (78 percent vs. 66 percent). Nearly 60 percent of women and men with a primary partner used a condom at last sex. Half as many (about 30 percent) of each said they always used a condom with their primary partner.

- Multiple partnerships: Nearly half of men (47 percent) and 7 percent of women reported two or more sexual partners in the last six months. More than a quarter of men (27 percent) who had a casual partner in the last six months did not use a condom with that partner at last sex.

\section{INTIMATE PARTNER VIOLENCE}

-Women's experiences: More than a quarter of women (27 percent) with a primary sexual partner reported physical or sexual violence in the last six months. About a third of women (34 percent) reported experiencing any type of violence-physical, sexual, or emotional.

- Men's perpetration: About one in five men (19 percent) reported perpetrating any type of violence in the last six months. Differences in women's and men's report of violence was greatest for emotional violence.

\section{HIV CARE CONTINUUM}

In 2015 South Africa adopted the UNAIDS 9090-90 targets, which specify that, by 2020, 90 percent of all people living with HIV will know their status, 90 percent of people diagnosed with HIV infection will receive antiretroviral therapy (ART), and 90 percent of people receiving ART will achieve viral suppression. Our study suggests that many who live in informal settlements do indeed know their status, but considerable shortfalls remain before diagnosis and treatment 
utilization goals can be achieved. As this study did not collect data on viral suppression, further research is needed to provide a more complete picture.

- $\quad$ HIV testing: In the past six months, most respondents had received an HIV test. About fourfifths (81 percent) of women were tested for HIV and received the results compared to 67 percent of men $(p<0.0001)$.

- HIV status: Nearly one in three women (ages 18-24) reported living with HIV. This figure is twice as high as that for men (ages 18-35) (30 percent vs. 14 percent; $p<0.0001$ ).

- HIV treatment: Despite high levels of HIV prevalence, the proportion of respondents living with HIV who are on ART is quite low. Among those who tested positive, 25 percent of women and 38 percent of men reported being currently on treatment.

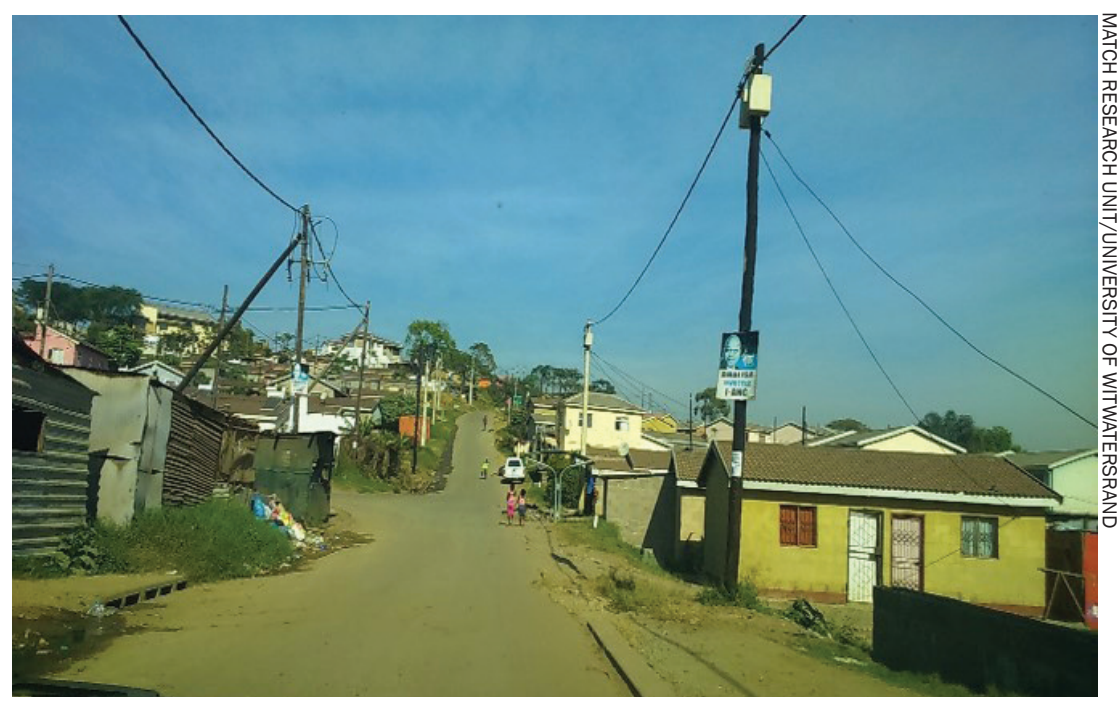

\section{IMPLICATIONS}

Young adult residents of these informal communities face many vulnerabilities to HIV, including economic insecurity, mobility, intimate partner violence, and unprotected sex.

People in informal settlements are being reached with HIV testing, likely reflecting the wide availability and promotion of HIV testing in

Figure 1 Study results vis-à-vis UNAIDS testing and treatment goals*

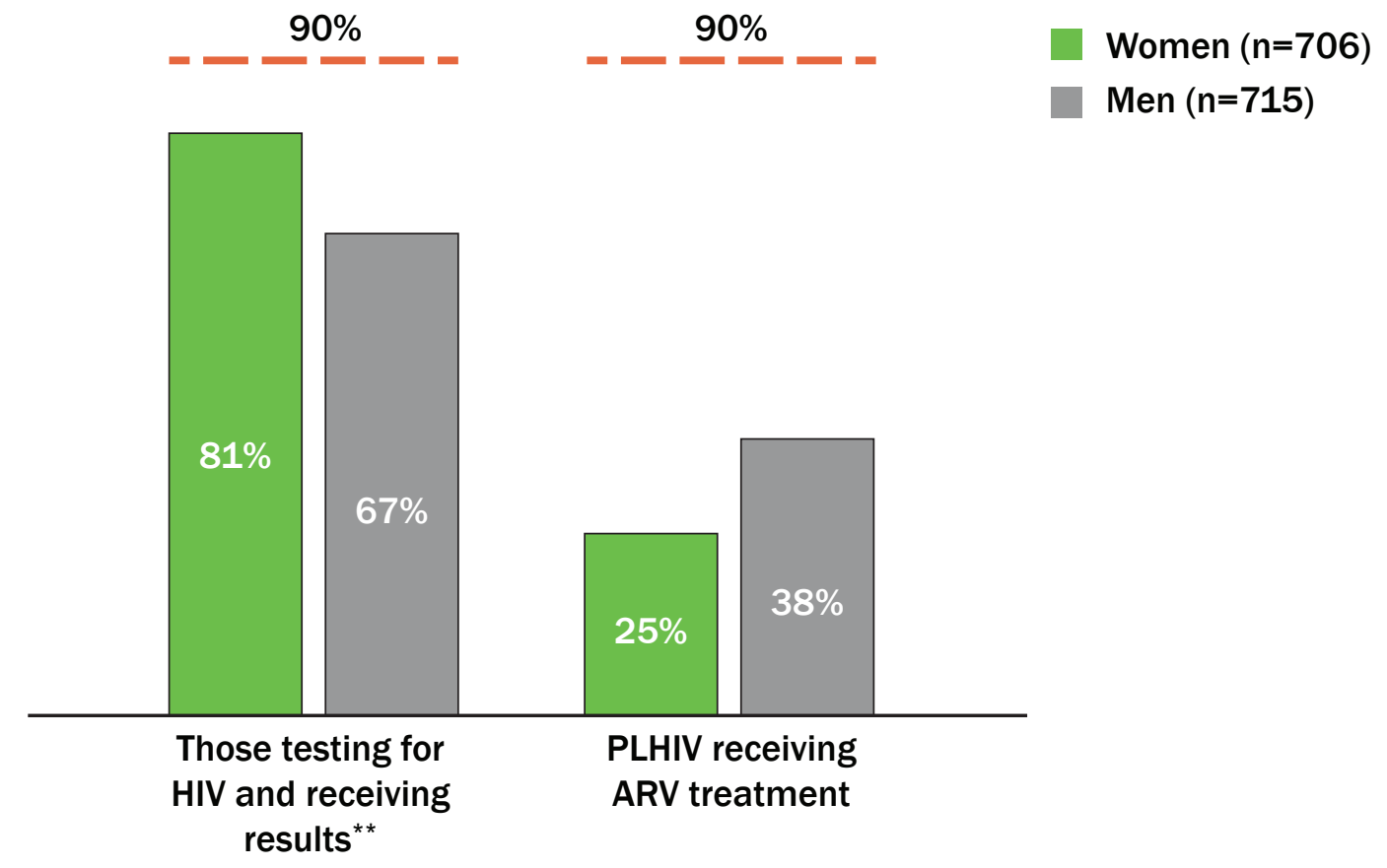

*Viral load not collected as part of the study.

** Excludes participants who had not tested in past $6 \mathrm{~m}$, but knew they were HIV+ (i.e. they had no need for testing) 
South Africa. Self-reported HIV prevalence in this study is high at 30 percent for young women, and 14 percent for young men, and reflective of the substantial epidemic in KZN, South Africa. One of the most recently published national surveys found that HIV prevalence was highest in KZN, at 17 percent (men and women combined), compared to 12 percent nationally (Shisana et al. 2014).

Of concern is that use of ART among residents of informal settlements living with HIV is very low, particularly among women. Data from a 2016 paper indicate that approximately 53 percent of all people living with HIV in KwaZulu-Natal were on ART (Huerga et al. 2016). In our study, only a quarter of women and 38 percent of men were on treatment.

These findings highlight the need for HIV treatment services to be more responsive to residents living with HIV in informal settlements. And continued efforts are needed to reduce HIV risk and intimate partner violence among young women and men in these communities.

\section{REFERENCES}

Housing Development Agency. 2013. "KwaZuluNatal: Informal settlements Status 2013." Johannesburg: Housing Development Agency.

Huerga, H. et al. 2016. "Who needs to be targeted for HIV testing and treatment in KwaZulu-Natal? Results From a population-based survey," J Acquir Immune Defic Syndr. 73(4): 411-418. https://www.ncbi.nlm.nih.gov/pmc/articles/ PMC5172512/]

Shisana, O, et al. 2014. South African National HIV Prevalence, Incidence and Behaviour Survey, 2012. Cape Town: HSRC Press. agreement funded by the President's Emergency Plan for AIDS Relief and the U. S. Agency for International Development (Agreement No. AIDOAA-A-14-00060). SOAR is able to accept funding from all USAID accounts.

Population Council leads the Project SOAR consortium in collaboration with Avenir Health, Elizabeth Glaser Pediatric AIDS Foundation, the Johns Hopkins University, Palladium, and The University of North Carolina at Chapel Hill.
Project SOAR/Population Council

4301 Connecticut Avenue, NW, Suite 280 Washington, DC 20008

Tel: +12022379400

e-mail: ProjectSOAR@popcouncil.org popcouncil.org/ProjectSOAR

(C)Population Council, October 2017 